\title{
Patterns of Alcohol Consumption and Acute Myocardial Infarction: A Case-Crossover Analysis
}

\author{
M.G. Gerlich ${ }^{\mathrm{a}, \mathrm{b}} \quad$ A. Krämer ${ }^{\mathrm{b}} \quad$ G. Gmel ${ }^{\mathrm{c}} \quad$ M. Maggiorini ${ }^{d} \quad$ T.F. Lüscher ${ }^{\mathrm{d}} \quad$ H. Rickli ${ }^{\mathrm{e}}$ \\ G.R. Klegere J. Rehm ${ }^{\mathrm{a}}$ f-h \\ ${ }^{a}$ Research Institute for Public Health and Addiction, Zurich, Switzerland; ' ${ }^{b}$ Department of Health Medicine, \\ University of Bielefeld, Germany; ' CSwiss Institute for the Prevention of Alcohol and Drug Problems, Lausanne, \\ ${ }^{\mathrm{d}}$ Department of Internal Medicine, University Hospital Zurich, Zurich, e Department of Internal Medicine, \\ Cantonal Hospital St. Gallen, St. Gallen, Switzerland; f Department of Public Health Sciences, University of Toronto, \\ ${ }^{g}$ Centre for Addiction and Mental Health, Toronto, Ont., Canada; ${ }^{\text {Ep }}$ idemiological Research Unit, \\ Technische Universität Dresden, Clinical Psychology and Psychotherapy, Dresden, Germany
}

\section{Key Words}

Acute myocardial infarction - Coronary heart disease .

Alcohol $\cdot$ Drinking patterns $\cdot$ Binge drinking $\cdot$ Case crossover

\begin{abstract}
Background: Alcohol consumption has been causally related to the incidence of coronary heart disease, but the role of alcohol before the event has not been explored in depth. This study tested the hypothesis that heavy drinking (binge drinking) increases the risk of subsequent acute myocardial infarctions (AMI), whereas light to moderate drinking occasions decrease the risk. Methods: Case-crossover design of 250 incident AMI cases in Switzerland, with main hypotheses tested by conditional logistic regression. Results: Alcohol consumption $12 \mathrm{~h}$ before the event significantly increased the risk of AMI (OR 3.1; 95\% Cl 1.4-6.9). Separately, the effects of moderate and binge drinking before the event on AMI were of similar size but did not reach significance. In addition, AMI patients showed more binge drinking than comparable control subjects from the Swiss general population. Conclusions: We found no evidence that alcohol consumption before the event had protective effects on AMI. Instead, alcohol consumption increased the risk.
\end{abstract}

Copyright $\odot 2009$ S. Karger AG, Basel

\section{KARGER}

Fax +41613061234 E-Mail karger@karger.ch www.karger.com (c) 2009 S. Karger AG, Basel

$1022-6877 / 09 / 0153-0143 \$ 26.00 / 0$

Accessible online at:

www.karger.com/ear

\section{Introduction}

Regular moderate alcohol consumption without heavy drinking has been shown to be a protective factor for cardiovascular disease including acute myocardial infarction (AMI) in particular $[1,2]$. Other protective factors include regular physical activity and daily consumption of fruits and vegetables, whereas hyperlipidemia, smoking, hypertension, diabetes mellitus and obesity have been identified as major modifiable risk factors for AMI $[3,4]$. Furthermore, psychosocial stress has been linked to an increased risk for AMI [5, 6], and mental illness, such as depression, has been shown to be an independent predictor of coronary heart disease (CHD) events $[7,8]$.

Studies have also explored the influence of certain exposures shortly before the event, and factors such as heavy physical exertion [9-11], anger [12,13] and consumption of cocaine [14] or marijuana [15] have been observed to be potential triggers of AMI onset. While extensive research has examined the influence of usual or regular alcohol use on CHD outcomes, the influence of alcohol consumption prior to the event has received little attention. Some case reports of men under the age of 40 have

E-Mail miriam.gerlich@isgf.uzh.ch 
discussed heavy acute alcohol intake as a potential trigger for AMI [16-19], but only a few studies in the literature have systematically investigated the effect of alcohol exposure shortly before $\mathrm{CHD}$ events using a case-crossover or case-control design [20-22]. Moreover, the results of these controlled studies have been mixed.

The influence of binge drinking is of particular interest in this analysis. In a recent study of alcohol drinking patterns and myocardial infarction (MI) in women, those who drank at least once a month in a way that 'their speech was slurred or they became unsteady on their feet', a behavior classified as 'intoxication', had nearly a threefold risk of MI when compared to lifetime abstainers. Among current drinkers, women who drank to intoxication once or more per month had a sixfold increased likelihood of MI [23].

As reviewed by McKee and Britton [24] and further sources $[1,2]$, a number of possible mechanisms have been discussed in the literature explaining the acute effects of binge drinking on CHD events. These include increased blood clotting and reduced threshold for ventricular fibrillation: (i) Binge drinking has been shown to increase low-density lipoproteins, which in turn are linked to cardiovascular morbidity and mortality. Contrary to low or moderate steady drinking, heavy irregular drinking has not been associated with increased levels of high-density lipoproteins, which are linked to favorable cardiovascular outcomes. (ii) Binge drinking has been associated with an increased risk of thrombosis, occurring after cessation of a heavy drinking episode. (iii) Binge drinking appears to predispose drinkers to histological changes in the myocardium and conducting system, as well as to a reduction in the threshold for ventricular fibrillation. Kauhanen et al. [25] suggested that 'heavy acute intake of beer may involve acute triggers of severe pathophysiological events in the myocardium or the coronary arteries, or both. These events might include arrhy thmia, ischaemia, and possibly thrombotic processes'. Binge drinking has been shown to increase the risk of calcification of blood vessels [26] as well as that of major coronary events, independent of previous history of CHD [25, 27-29].

A cardioprotective effect of light to moderate drinking has been shown when compared with lifetime abstainers as a control group in regular alcohol use [23, 28, 30-32], as well as shortly before CHD events [20,21]. Based on these epidemiological findings, this study tested the hypothesis that heavy drinking occasions (binge drinking) increase the risk of subsequent AMI, whereas light to moderate drinking occasions decrease the risk.

\section{Methods}

\section{Study Population and Data Collection}

Patients were recruited in three major hospitals in the German-speaking part of Switzerland - a university hospital, a county hospital and a city hospital. Interviews based on a standardized questionnaire were conducted in the hospitals by trained staff of the Research Institute or by trained hospital staff. Interview training included test interviews with staff of the research institute as well as supervised interviews in the hospitals. Through collaboration with the staff it was also possible to track all 673 patients who were hospitalized for first time AMI (ICD I21; for detailed definition see below) in the study hospitals between July 26, 2005 and November 15, 2006. We used the following definition of AMI which is compatible with the national register for Acute Myocardial Infarction in Switzerland (AMIS-plus database): symptoms and/or ECG changes compatible with acute coronary syndrome and with the enzymes creatine kinase or creatine kinase-muscle brain at least twice the upper limits of normal.

256 interviews were conducted, 6 of which could not be included in the analysis as essential data for testing the main hypotheses (date and time of AMI) were missing. As a result, the study group consisted of 250 patients. The major reason why not all 673 patients were eligible for interviews was the early relocation of 239 patients (35.5\%) within $24 \mathrm{~h}$ to another hospital, mainly because of regional responsibility and bed availability. These patients were, by definition, not eligible for our study. We arranged with the hospitals that patients were not to be interviewed on their first day in hospital, in order to not disturb medical examinations, and in consideration of the patients with recent major complications. In some cases the health status of the patient allowed an earlier timing of the interview; the situation was discussed with the medical staff, referring to each case individually. The other exclusion criteria were: no domicile in Switzerland (tourists) (5 persons, 0.7\%); insufficient skills in German language $(29,4.3 \%)$; mental or physical inability to participate in an interview (e.g. cerebral damages, dementia, aphasia, hypoxia, patient too confused) (55 persons, 8.2\%) or death after admission $(12,1.8 \%)$, involvement in another interview study (17 persons, $2.5 \%$ ) or other (e.g. the patient left the hospital without official discharge) (4 persons, $0.6 \%$ ). The eligible sample consisted therefore of 312 patients. Of those, 56 patients (18\%) refused to participate in the interview study. As such, the overall response rate among eligible patients was $82 \%$.

Since we collected the time of the event as well as the time of the interview, the corresponding time span between AMI and interview could be gathered for each interview. The interviews were conducted in half of the study population within $38 \mathrm{~h}$ after the AMI. 55\% of the patients were referred directly to the study hospital and $45 \%$ were transferred from another hospital to the study hospital. The patients who refused to participate in the interview did not differ in gender distribution with the patients who participated in the interviews, but they were on average 8 years older.

\section{Study Design}

The case-crossover methodology used in the present study was introduced by Maclure [33] in the early 1990s to study transient effects on the risk of rare acute events. The case-crossover design basically tries to answer the question: Was this event trig- 
gered by something unusual that happened just before the incident [34]?

We used this design to assess the change in risk of AMI during a 'hazard period' after exposure to alcohol and other potential triggers of AMI onset. An important feature of the case-crossover design is that the control information for each patient is based on his or her own past exposure experience. Thus, there is no external control group as in the case-control design, but each case serves as its own control. It is possible to define one or more control points or time periods, respectively. This design was invented to circumvent potential control bias by using controls from the general population or by using other patients as controls [34].

The $12 \mathrm{~h}$ immediately preceding the AMI were considered a hazard period. The patient was first asked to report time of infarction. Alcohol consumption in this hazard period was compared with the corresponding time period 1 week prior. Patients were then asked to report what they were doing during the control period, if there were unusual events and if they were drinking alcohol, what type, the amount and the time of consumption, as exact as possible.

In addition, we compared the drinking patterns of our patients with the drinking patterns of the Swiss general population of similar sex and age in order to explore whether our sample differed with regard to alcohol consumption.

\section{Alcohol Consumption}

Participants were asked in detail about their drinking behavior: frequency, including binge drinking, type (e.g. wine, beer, spirits), and amount on a usual drinking occasion in deciliters (dl).

Drinking Status. Patients who drank at least once a month during the 3 months prior to the interview were defined as current drinkers. Patients who did not drink at least once a month during the 3 months prior, but drank once a month during some period of their life, were defined as former drinkers. Patients who drank alcohol during some period of their life, but always less than once a month, were classified as occasional drinkers. Patients who never drank alcohol in their life (apart from sips) were defined as lifetime abstainers. These categories were used in a landmark study by Jackson et al. [21, 35], who first examined the short-term influence of alcohol intake on the risk of CHD events via the casecrossover design.

Volume of Ethanol. Using the amount of alcoholic beverages in deciliters as well as the type of beverage, standard glasses with $12 \mathrm{~g}$ ethanol were calculated corresponding to $1.2 \mathrm{dl}$ wine, $3 \mathrm{dl}$ beer, $0.38 \mathrm{dl}$ spirits or $0.8 \mathrm{dl}$ fortified wine (e.g. port), respectively.

Heavy Drinking Occasions (Binge Drinking). Definitions of the term binge drinking vary. The common international definition of Wechsler and colleagues [36] characterizes binge drinking as an episodic, heavy drinking occasion, with 4 or more drinks of alcohol for women (minimum of $48 \mathrm{~g}$ ethanol) and 5 or more drinks for men (minimum of $60 \mathrm{~g}$ ethanol) [37]. Since the largest scale survey in Switzerland, The Swiss Health Survey [38], defined heavy drinking occasions as 6 or more drinks for women and 8 or more drinks for men, we additionally asked the patients about this standard in order to compare the heavy drinking patterns of our sample with those of the general population of Switzerland. The categories regarding the frequency of binge drinking in the prior year were as follows: never, less than once a month, every month, every week, (almost) every day [38].

Patterns of Alcohol Consumption and Acute Myocardial Infarction
Basic Medical Data

Basic medical data were obtained from the medical records of the patients with informed consent. Information was obtained on the presence of arterial hypertension (documented pressure $>140 / 90$ ), hyperlipidemia, diabetes mellitus and prior angina pectoris as well as regular medication before the event. Further data such as smoking history, weight, height, family history of MI, etc. was asked about in our questionnaire. Our study was approved by the responsible cantonal research ethics boards of the participating hospitals.

\section{Statistical Analysis}

Conditional logistic regression was used to estimate the odds ratios for alcohol consumption in general and binge drinking, within the time before the AMI compared to the same time span 1 week prior [39]. Conditional regression tries to answer the question of a causal impact of drinking before the event. The sample size was determined a priori, in order to detect a difference in proportions of $10 \%$ when the proportion of discordant pairs was expected to be $30 \%$ and the method analysis was a McNemar's test of equality of paired proportions with a 0.05 two-sided significance level. Our sample size of 250 patients corresponded to a power of $83 \%$.

Logistic regression was carried out to additionally compare the impact of different social and other characteristics on drinking before the AMI.

Furthermore, we compared the usual drinking patterns of our sample with the Swiss Health Survey conducted in the year 2002 [38]. This sample comprised of 19,706 individuals older than 15 years and living in Switzerland (Swiss or foreign nationality), who were interviewed by phone and 16,141 of whom also completed a written questionnaire. Comparisons between the patterns of alcohol consumption between our sample and the general population were carried out by first computing comparable rates for different drinking categories, which were directly standardized to the sex and age distribution of the AMI patients [40]. The following age categories were used: $15-39,40-49,50-59,60-69,70+$. These rates were then compared using table analysis, resulting in a likelihood ratio $\chi^{2}$ to test for overall differences between samples and standardized residuals to test for deviation of a cell from expected value. For the latter, an absolute value of $>2$, corresponding to a $5 \%$ significance level, was fixed as criterion for significance [41].

\section{Results}

\section{Description of the Sample}

In table 1, sociodemographic characteristics of the study population are shown. The study group consisted mainly of men (79.2\%) with an average age of 59.7 years (range 29-88).

In table 2, the risk profile at admission is presented. Most AMI occurred in the morning hours, 33.2\% (83) were between 06:00 and 11:59 h. The beginning of the week was overrepresented as time of occurrence of the event. None of the patients had a cardiac rupture, $52 \%$ of 
Table 1. Characteristics of the study group $(n=250)$

\begin{tabular}{|c|c|}
\hline Characteristics & $\mathrm{n}^{1}$ (valid \%) \\
\hline \multicolumn{2}{|l|}{ Sex } \\
\hline Male & $198(79.2)$ \\
\hline Female & $52(20.8)$ \\
\hline Age, years & $59.7 \pm 12.4$ \\
\hline$<50$ & $55(22.0)$ \\
\hline $50-59$ & $64(25.6)$ \\
\hline $60-69$ & $72(28.8)$ \\
\hline $70+$ & $59(23.6)$ \\
\hline \multicolumn{2}{|l|}{ Nationality } \\
\hline Swiss & $202(80.8)$ \\
\hline Other & $48(19.2)$ \\
\hline \multicolumn{2}{|l|}{ Marital status } \\
\hline Never married & $23(9.2)$ \\
\hline Divorced & $46(18.4)$ \\
\hline Married & $163(65.2)$ \\
\hline Widowed & $18(7.2)$ \\
\hline \multicolumn{2}{|l|}{ Education (highest certificate) } \\
\hline No school leaving certificate & $3(1.2)$ \\
\hline Obligatory school (9 years) & $32(13.0)$ \\
\hline Vocational education & $127(51.4)$ \\
\hline Higher school education (12 years) & $7(2.8)$ \\
\hline Higher education $^{2}$ & $78(31.6)$ \\
\hline \multicolumn{2}{|l|}{ Employment status } \\
\hline Full time (100\%) & $105(42.2)$ \\
\hline Part time & $20(8.0)$ \\
\hline Pension & $105(42.2)$ \\
\hline Other & $19(7.6)$ \\
\hline
\end{tabular}

\footnotetext{
${ }^{1}$ Differences to 250 are due to missing values.

${ }^{2}$ Upper vocational school, school of applied sciences, university.
}

the patients were hypertensive and $35.6 \%$ had the diagnosis of hyperlipidemia.

Of the study population, $74.8 \%$ (187) were current drinkers. $16.4 \%$ of the sample reported daily drinking, with 3 patients ( $1.2 \%$ of the study group) drinking more than once a day. Among the weekly non-daily drinkers, most people drank 1-4 times a week. Only 5 patients ( $2 \%$ of the whole study group) drank 5-6 times a week. Table 3 also provides information about the beverage choice in men and women, mainly wine and beer for men, and wine for women. 15 out of the 159 current male drinkers $(9.4 \%)$ drank 5 or more glasses on a usual drinking occasion. In current female drinkers, 2 out of $28(7.2 \%)$ drank 4 or more glasses normally. About three quarters of the current drinkers did not change the quantity of drinking in the last 12 months.
Table 2. Risk profile at admission $(\mathrm{n}=250)$

\begin{tabular}{|c|c|}
\hline Health anamnesis & $\mathrm{n}^{1}($ valid \%) \\
\hline \multicolumn{2}{|l|}{ Time of AMI } \\
\hline 00:00-05:59 h & $53(21.2)$ \\
\hline $06: 00-11: 59 \mathrm{~h}$ & $83(33.2)$ \\
\hline $12: 00-17: 59 \mathrm{~h}$ & $67(26.8)$ \\
\hline $18: 00-23: 59 \mathrm{~h}$ & $47(18.8)$ \\
\hline \multicolumn{2}{|l|}{ Day of AMI } \\
\hline Monday & $40(16.9)$ \\
\hline Tuesday & $53(21.2)$ \\
\hline Wednesday & $24(9.6)$ \\
\hline Thursday & $21(8.4)$ \\
\hline Friday & $26(10.4)$ \\
\hline Saturday & $31(12.4)$ \\
\hline Sunday & $55(22.0)$ \\
\hline \multicolumn{2}{|l|}{ Smoking } \\
\hline Never & $74(29.6)$ \\
\hline Current smoker & $110(44.0)$ \\
\hline Former smoker & $66(26.4)$ \\
\hline \multicolumn{2}{|l|}{ Medical history } \\
\hline Angina pectoris & $12(4.9)$ \\
\hline Hypertension & $130(52.0)$ \\
\hline Hyperlipidemia & $89(35.6)$ \\
\hline Diabetes mellitus & $23(9.2)$ \\
\hline Obesity $^{2}$ & $39(15.6)$ \\
\hline BMI (average) & $26.7 \pm 4.1$ \\
\hline \multicolumn{2}{|l|}{ Family history of $\mathrm{MI}^{3}$} \\
\hline Yes & $29(11.7)$ \\
\hline \multicolumn{2}{|c|}{ Medication use before MI (regular use) } \\
\hline Aspirin $^{4}$ & $39(17.7)$ \\
\hline Calcium channel blocker & $14(6.6)$ \\
\hline$\beta$-Blockers & $40(18.6)$ \\
\hline ACE inhibitors & $26(12.1)$ \\
\hline \multicolumn{2}{|c|}{$\begin{array}{l}{ }^{1} \text { Differences to } 250 \text { are due to missing values. } \\
{ }^{2} \text { Obesity defined as } \mathrm{BMI} \geq 30 \mathrm{~kg} / \mathrm{m}^{2} . \\
{ }^{3} \mathrm{MI} \text { of parents under the age of } 60 . \\
{ }^{4} \text { Aspirin or other inhibitors of platelet aggregation. }\end{array}$} \\
\hline
\end{tabular}

\section{Drinking Patterns in the Hazard and Control Period}

Drinking any alcohol in the 12-hour hazard period increased the risk for the event threefold (OR 3.1; 95\% CI 1.4-6.9). 25 individuals were exposed in the hazard period and 8 individuals in the control period.

Moderate drinking was defined as drinking up to $24 \mathrm{~g}$ of pure alcohol for women and up to $36 \mathrm{~g}$ for men. Drinking moderately in the 12 -hour hazard period increased the risk of AMI marginally significant compared with no alcohol consumption (OR 2.3; 95\% CI 0.97-5.2). 18 persons were exposed in terms of moderate drinking in the hazard period and 8 persons were exposed in the control period. 
Table 3. Alcohol consumption

\begin{tabular}{|c|c|c|}
\hline Drinking characteristics & $\begin{array}{l}\text { Men }(\mathrm{n}=198) \\
\mathrm{n}(\text { valid \% of men) }\end{array}$ & $\begin{array}{l}\text { Women }(\mathrm{n}=52) \\
\mathrm{n}(\text { valid } \% \text { of women })\end{array}$ \\
\hline a. Lifetime abstainers & $6(3.0)$ & $7(13.5)$ \\
\hline b. Former drinkers ${ }^{1}$ & $14(7.1)$ & $5(9.6)$ \\
\hline c. Less than once a month (occasional drinkers) & $19(9.6)$ & $12(23.1)$ \\
\hline d. Less than weekly, at least once a month & $35(17.7)$ & $8(15.4)$ \\
\hline e. Weekly non-daily drinkers & $88(44.4)$ & $15(28.8)$ \\
\hline f. Daily drinkers & $36(18.2)$ & $5(9.6)$ \\
\hline \multicolumn{3}{|l|}{ Kind of beverage usually consumed in the last 3 months ${ }^{2}$} \\
\hline Beer & $82(51.6)$ & $8(28.6)$ \\
\hline Wine & $136(85.5)$ & $25(89.3)$ \\
\hline Fortified wine ${ }^{3}$ & $3(1.9)$ & $1(3.6)$ \\
\hline Spirits & $34(21.4)$ & $7(25.0)$ \\
\hline \multicolumn{3}{|c|}{ Amount of glasses at a usual drinking occasion last 3 months ${ }^{4}$} \\
\hline Less than 2 glasses & $63(39.6)$ & $17(60.7)$ \\
\hline $2-2.9$ glasses & $36(22.6)$ & $6(21.4)$ \\
\hline 3-3.9 glasses & $27(17.0)$ & $3(10.7)$ \\
\hline $4-4.9$ glasses & $18(11.3)$ & $1(3.6)$ \\
\hline 5 or more glasses & $15(9.4)$ & $1(3.6)$ \\
\hline \multicolumn{3}{|c|}{ Compared to the last 12 months, how much did you drink in the last few weeks? ${ }^{4}$} \\
\hline More & $12(7.5)$ & $3(10.7)$ \\
\hline Less & $27(17.0)$ & $7(25.0)$ \\
\hline About the same & $120(75.5)$ & $18(64.3)$ \\
\hline \multicolumn{3}{|c|}{$\begin{array}{l}{ }^{1} \text { Drank in the past at least once a month, but not in the last } 3 \text { months. } \\
{ }^{2} \text { More than one answer is possible, so the total exceeds } 100 \% \text {. } \\
{ }^{3} \text { Drinks with about } 15-20 \% \text { alcohol, e.g. port wine, sherry. } \\
{ }^{4} \% \text { related to categories d, e, f of drinking status (current drinkers). }\end{array}$} \\
\hline
\end{tabular}

We did not find any significant differences regarding binge drinking before AMI, using the international definition of 4 or more for women and 5 or more glasses of alcohol for men (see Method section). In the 12-hour period before the AMI, 3 individuals were exposed in terms of binge drinking and 1 person was exposed in the control period (OR 3.0; 95\% CI 0.3-28.8).

In a logistic regression analysis, our results were not influenced significantly by the following parameters: age, gender, smoking status, family history of AMI, hypertension, hyperlipidemia, diabetes mellitus, prior unstable angina pectoris, physical exertion shortly before the event, e.g. jogging or carrying heavy things, heavy psychological exposure in the $12 \mathrm{~h}$ before AMI, e.g. death of a family member or a conflict assessed as heavy emotional strain by the patient, or cocaine use in the $12 \mathrm{~h}$ prior to the AMI.

\section{Comparison of Drinking Patterns with the General Population}

Patterns of alcohol consumption varied significantly between AMI patients and the general population (likelihood ratio $\chi^{2}$ : 40.0; d.f. $=3$; $\mathrm{p}<0.001$ ). Compared to the general population, AMI patients had less lifetime abstention (standardized rates: 5.2 vs. $11.8 \%$ ), were more often former drinkers (7.6 vs. $4.8 \%$ ), more often irregular, i.e. less than weekly, drinkers (29.6 vs. $16.2 \%)$ and less often weekly drinkers (57.6 vs. $67.0 \%$ ). The standardized residuals were significant for the categories of abstention and irregular drinking. In addition, binge drinking occasions were significantly more frequent among AMI patients: both 'less than monthly' (20.7 vs. $10.9 \%)$ and 'monthly or more frequent' binge drinking occasions were about twice as prevalent in our study population (6.8 vs. 3.4\%). Both rates had significant standardized residuals of 4.4 and 2.7 , respectively. 


\section{Discussion}

In this case-crossover study on first non-fatal AMI in men and women, we found that drinking alcohol $12 \mathrm{~h}$ before the AMI increased the risk for such an event. However, we had no indication that binge drinking was of particular importance in triggering AMI. The odds ratios for binge drinking in the 12-hour period before the event were of the same magnitude as for alcohol in general, but did not reach significance due to the small sample size. Our hypothesis that drinking moderately shortly before the event decreases the risk of AMI, while binge drinking results in an increase, could not be confirmed. However, a comparison of alcohol drinking patterns in AMI patients to the general population revealed that binge drinking was more prevalent in our sample. Thus, the results of our study give further support to the hypothesis that irregular alcohol intake, with binge drinking episodes in particular, has detrimental effects on CHD morbidity and mortality [20, 25, 28, 42, 43].

Obviously, our study is not without limitations. $\mathrm{Pa}$ tients knew that the interview would be about risk factors and MI, and that there would be questions on alcohol consumption in order to explore its relationship to MI. However, in order to minimize bias, patients and interviewers were blinded to the explicit study hypothesis.

The patients were recruited in three urban hospitals. However, as patients from suburban or rural hospitals are often referred to these hospitals for further examinations and therapy, almost half of our study population was based outside the city. Though a selection bias due to the location of our study hospitals or referral practice cannot be fully excluded, it does not seem to be likely to influence our results substantially.

The self-matching feature of the case-crossover design used in this study eliminates the problems of control selection, but recall bias cannot be excluded. In our study the control condition of the 12-hour hazard period before the event was the corresponding time period 1 week prior. This control condition was chosen to assure comparability within the day of the week, since drinking behavior varies between working days and weekends, e.g. some individuals only drink on weekends $[44,45]$. While the chosen design controls for a potential effect of day of the week, the possibility that recall bias is larger for the events of 1 week prior compared to more recent time periods, cannot be excluded. This is especially the case for sporadic drinkers where recall bias may influence results [46].

Studies on acute alcohol consumption and risk of acute $\mathrm{CHD}$ events have yielded conflicting results. For example, a case-crossover study from Slovenia examining the role of coffee and alcohol consumption as triggering factors of sudden cardiac death, found that alcohol consumption within $2 \mathrm{~h}$ before the event resulted in an increased risk for persons with other risk factors for CHD [22]. Two casecontrol studies conducted in New Zealand respectively Australia on the relationship between drinking patterns and AMI and coronary death showed a protective effect of acute alcohol consumption, which are therefore in contrast to our results. The first study examining the risk of nonfatal AMI and coronary death showed that for all drinking categories alcohol consumption before the event was protective (overall risk of AMI in the $24 \mathrm{~h}$ before the event: 0.75 in men and 0.61 in women). Since few participants in this study reported heavy drinking in the period examined, the authors stated that they were not able to comment on the risk of an acute coronary syndrome associated with binge drinking [21]. The second study showed an acute protective effect of alcohol consumption for regular female drinkers (drinking at least once a week) who consumed one or two drinks in the $24 \mathrm{~h}$ preceding the onset of symptoms, while a non-significant association was observed for men [20].

Our results did not show a significant effect of binge drinking shortly before the event, but numbers of exposed cases were small. However, given the facts that drinking prior to the event resulted in an increased risk for AMI and that a comparison with the general population of a similar sex and age distribution showed higher rates of previous year heavy drinking occasions in our sample, the hypothesis that heavy drinking occasions lead to an increase in risk for AMI received some support. Nevertheless, more research is needed to further explore this hypothesis.

\section{Acknowledgements}

The authors are indebted to the patients and health professionals of the hospitals for participation in the study. We would like to give a special thanks to O. Bertel and E. Straumann of the Department of Internal Medicine at the City Hospital Triemli in $\mathrm{Zu}-$ rich for the opportunity to interview patients in these units. We would also like to thank D. Radovanovic of the AMIS-plus Data Center of the University of Zurich for helpful background information and R. Jackson of the University of Auckland for provision of the special case-crossover items. Finally, we would like to thank D. Hiltebrand of the Research Institute for Public Health and Addiction for technical assistance, and F. Kanteres and D. Baliunas of the University of Toronto for the English copyediting of the text and valuable comments on earlier versions.

This work was supported by the Swiss Foundation of Alcohol Research (SSA) and the Swiss National Science Foundation (SNF). 


\section{References}

1 Puddey IB, et al: Influence of pattern of drinking on cardiovascular disease and cardiovascular risk factors - a review. Addiction 1999;94:649-663.

2 Rehm J, Sempos CT, Trevisan M: Average volume of alcohol consumption, patterns of drinking and risk of coronary heart disease - a review. J Cardiovasc Risk 2003;10: 15-20.

3 YusufS, et al: Effect of potentially modifiable risk factors associated with myocardial infarction in 52 countries (the INTERHEART study): case-control study. Lancet 2004; 364:937-952.

4 Stamler J: Established major coronary risk factors: historical overview; in Marmot M, Elliott P (eds): Coronary Heart Disease Epidemiology. From Aetiology to Public Health. New York, Oxford Medical Publications, 2005, pp 19-31.

5 Anand SS, et al: Risk factors for myocardial infarction in women and men: insights from the INTERHEART Study. Eur Heart J 2008; 29:932-940.

6 Rosengreen A, et al: Association of psychosocial risk factors with risk of acute myocardial infarction in 11,119 cases and 13,648 controls from 52 countries (the INTERHEART Study): case-control study. Lancet 2004;364:953-962.

7 Stansfeld S, Rasul F: Mental illness and coronary heart disease; in Marmot M, Elliott $\mathrm{P}$ (eds): Coronary Heart Disease Epidemiology. From Aetiology to Public Health. New York, Oxford Medical Publications, 2005, pp 414-431.

8 Rugulies R: Depression as a predictor for coronary heart disease. Am J Prev Med 2003; 23:51-61.

9 Mittleman MA, et al: Triggering of acute myocardial infarction by heavy physical exertion. Protection against triggering by regular exertion. Determinants of Myocardial Infarction Onset Study Investigators. N Engl J Med 1993;329:1677-1683.

10 Willich SN, et al: Physical exertion as a trigger of acute myocardial infarction. Triggers and Mechanisms of Myocardial Infarction Study Group. N Engl J Med 1993;329:16841690.

11 Hallqvist J, et al: Does heavy physical exertion trigger myocardial infarction? A casecrossover analysis nested in a populationbased case-referent study. Am J Epidemiol 2000;151:459-467.

12 Verrier RL, Mittelman MA: Life-threatening cardiovascular consequences of anger in patients with coronary heart disease. Cardiol Clin 1996;14:289-307.

13 Möller J, et al: Do episodes of anger trigger myocardial infarction? A case-crossover analysis in the Stockholm Heart Epidemiology Program 8 (SHEEP). Psychosom Med 1999;61:842-849.
14 Mittleman MA, et al: Triggering of myocardial infarction by cocaine. Circulation 1999; 99:2737-2741.

15 Mittleman MA, et al: Triggering myocardial infarction by marijuana. Circulation 2001; 103:2805-2809.

16 Biyik I, Ergene O: Acute myocardial infarction associated with heavy alcohol intake in an adolescent with normal coronary arteries. Cardiol Young 2006;16:190-192.

17 Gowda RM, et al: Alcohol-triggered acute myocardial infarction. Am J Ther 2003;10 71-72.

18 Moreyra AE, et al: Acute myocardial infarction in patients with normal coronary arteries after acute ethanol intoxication. Clin Cardiol 1982;5:425-430.

19 Murphy JC, Campell NPS, McKeown PP: Alcohol induced myocardial infarction in two young brothers. Int J Cardiol 2008;127:e145e147.

20 McElduff P, Dobson AJ: How much alcohol and how often? Population-based case-control study of alcohol consumption and risk of a major coronary event. BMJ 1997;314:11591164.

21 Jackson R, Scragg R, Beaglehole R: Does recent alcohol consumption reduce the risk of acute myocardial infarction and coronary death in regular drinkers? Am J Epidemiol 1992;136:819-824.

22 Šelb Šemerl J, Šelb K: Coffee and alcohol consumption as triggering factors for sudden cardiac death: case-crossover study. Croat Med J 2004;45:775-780.

23 Dorn J, et al: Alcohol drinking pattern and non-fatal myocardial infarction in women. Addiction 2007;102:730-739.

24 McKee M, Britton A: The positive relationship between alcohol and heart disease in Eastern Europe: potential physiological mechanisms. J R Soc Med 1998;91:402-407.

25 Kauhanen J, et al: Beer drinking and mortality: results from the Kuopio Ischemic Heart Disease Risk Factors Study, a prospective population-based study. Br Med J 1997;315: 846-851.

26 Pletcher MJ, et al: Alcohol consumption, binge drinking and early coronary calcification: findings from the Coronary Artery Risk Development in Young Adults (CARDIA) Study. Am J Epidemiol 2005; 161:423433.

27 Wannamethee SG, Shaper AG: Alcohol and sudden cardiac death. Br Heart J 1992;68: 443-448.

28 Murray RP, et al: Alcohol volume, drinking pattern, and cardiovascular disease morbidity and mortality: is there a U-shaped function? Am J Epidemiol 2002;155:242-248.

29 Mukamal KJ, et al: Binge drinking and mortality after acute myocardial infarction. Circulation 2005;112:3839-3845.

30 Schroder H, et al: Myocardial infarction and alcohol consumption: a population-based case-control study. Nutr Metab Cardiovasc Dis 2006; 17:609-615.
31 Wells S, Broad J, Jackson R: Alcohol consumption and its contribution to the burden of coronary heart disease in middle-aged and older New Zealanders: a populationbased case-control study. N Z Med J 2004; 117:1-14

32 Rehm J, et al: Alcohol consumption and coronary heart disease morbidity and mortality. Am J Epidemiol 1997;146:495-501.

33 Maclure M: The case-crossover design: a method for studying transient effects on the risk of acute events. Am J Epidemiol 1991; 133:144-153.

34 Maclure M, Mittleman MA: Should we use a case-crossover design? Annu Rev Public Health 2000;21:193-221.

35 Marshall RJ, Wouters S, Jackson RT: A casecrossover analysis of a case-control study of alcohol consumption and coronary events: the effects of exposure definition and the use of control data. J Epidemiol Biostat 2000;5: 367-373.

36 Wechsler H, Nelson TF: Binge drinking and the American college student: what's five drinks? Psychol Addict Behav 2001;15:287291.

37 Gmel G, Rehm J, Kuntsche E: Binge drinking in Europe: definitions, epidemiology, and consequences. Sucht 2003;49:105-116.

38 Swiss Federal Statistical Office (ed): SchweizerischeGesundheitsbefragung 2002. Erste Ergebnisse. Neuchâtel, Swiss Federal Statistical Office, 2003.

39 Marshall RJ, Jackson RT: Analysis of casecrossover designs. Stat Med 1993;12:23332341.

40 Rothmann KJ, Greenland S: Modern Epidemiology. Philadelphia, Lippincott-Raven, 1998

41 Kennedy J: Analyzing Qualitative Data Log-Linear Analysis for Behavioral Research. New York, Praeger, 1992.

42 Laatikainen T, et al: Increased mortality related to heavy alcohol intake pattern. J Epidemiol Community Health 2003;57:379384.

43 Bagnardi $\mathrm{V}$, et al: Does drinking pattern modify the effect of alcohol on the risk of coronary heart disease? Evidence from a meta-analysis. J Epidemiol Community Health 2008;62:615-619.

44 Trevisan M, et al: Drinking pattern and risk of non-fatal myocardial infarction: a population-based case-control study. Addiction 2003;99:313-322.

45 Kabagambe EK, et al: Alcohol intake, drinking patterns, and risk of nonfatal acute myocardial infarction in Costa Rica. Am J Clin Nutr 2005;82:1336-1345.

46 Gmel G, Daeppen JB: Recall bias for sevenday recall measurement of alcohol consumption among emergency department patients: implications for case-crossover designs. J Stud Alcohol Drugs 2007;68:303-310. 